\title{
EFFECT OF INTRA-ARTICULAR CORTICOSTEROID INJECTIONS ON TEMPOROMANDIBULAR JOINT STRUCTURE (EXPERIMENTAL STUDY)
}

\author{
Asmaa M.A.S. Ghazal* ${ }^{*}$ and Amany H. Nemat**
}

\begin{abstract}
Aim of the study: to evaluate the short term effect of corticosteroid injection on temporomandibular joint structure.

Materials and Methods: Thirty six adult rats with weight ranged between 150-200 gm were included in the current study with normally functioning temporomandibular joint. The rats were divided into three groups: A, B, and C. every group is divided into (2) sub-groups. Each subgroup had (6) rats. All rats of the group A were injected one time, $A_{1}$ sacrificed after one week, $A_{2}$ sacrificed after 2 weeks form injection. all rats of the group B were injected 2 times at ( $0 \& 6$ weeks), $\mathrm{B}_{1}$ sacrificed after one week from last injection, $\mathrm{B}_{2}$ sacrificed after 2 weeks form last injection. . all rats of the group $C$ were injected 3 times at ( $0,6 \& 12$ weeks), $C_{1}$ sacrificed after one week from last injection, $\mathrm{C}_{2}$ sacrificed after 2 weeks form last injection.
\end{abstract}

Results: injection of corticosteroids for the 3rd time showed signs of inflammatory invasion and fatty degeneration showed in all cases.

KEYWORDS: Temporomandibular joint, corticosteroids effect, depo-Medrol injection.

\section{INTRODUCTION}

Temporomandibular joint (TMJ) is classified as a compound joint, which by definition, needs 3 bones at least to articulate, but TMJ consist of only 2 bones which are the mandibular condyle that fits into the articular fossa of temporal bone. They are separated from direct articulation by the articular disc (meniscus) which serves as a non-ossified bone permitting complex movements of the joint. ${ }^{(1)}$

The common features of the synovial joints exhibited by this joint include a disk, bone, fibrous capsule, fluid, synovial membrane, and ligaments. However, the features that differentiate and make this joint unique are its articular surface covered by fibrocartilage instead of hyaline cartilage. ${ }^{(2)}$

* B.D.S 2004, Faculty of Oral and Dental Medicine, Cairo University.

** Professor of oral pathology, Head of Orodental Research Division, National Research Centre. 


\section{Diseases affect human temporomandibular joint}

1- Osteoarthritis (OA): Is the most common disease affecting the temporomandibular joint (TMJ). Different terms in addition to osteoarthritis such as, degenerative joint disease, degenerative arthritis, osteoarthrosis, arthrosis and arthritis deformans are used in different literature and reflect both the non-inflammatory and inflammatory changes that may take place in the TMJ. ${ }^{(3,4)}$

2- Capsulitis and synovitis: Inflammation of the capsular ligament may manifest with swelling and continuous pain localized to the joint. Movements that stretch the capsular ligament cause pain with resultant limitation of such movement. ${ }^{(5)}$

Edema in the retrodiscal tissue may cause anterior displacement of the condyle and an acute malocclusion with painful limitation of mandibular movements. ${ }^{(6)}$

\section{Corticosteroids}

\section{Mechanism of action of intra-articular steroid injections}

Steroids possess anti-inflammatory properties. On the cellular level, steroids are highly lipophilic and are believed to bind to the cell's nucleus. It is believed that steroids act by altering transcription. Intra-articular steroids seem to reduce the number of lymphocytes, macrophages, and mast cells. ${ }^{(7,8)}$

With the reduction of these inflammatory mediators, pain symptoms often are improved. Because they are injected locally, intra-articular steroids avoid most of the systemic effects of oral steroids, including muscle weakness, skin thinning resulting in easy bruising, peptic ulceration, and aggravation of diabetes. ${ }^{(9)}$
Complication of corticosteroids injection Most can be categorized as mild, moderate, severe or life threatening.

Dexamethasone is a corticosteroid commonly used in humans and domestic animals, particularly in the treatment of painful conditions. When articular cartilage cells were subjected to dexamethasone, cell proliferation was inhibited. Even more significant than that was the fact that dexamethasone induced cell apoptosis. ${ }^{(10)}$

High doses of corticosteroids are known to increase the risk of aseptic bone necrosis. ${ }^{(11)}$

The pharmacologic effect of intra-articular methylprednisolone lasts 3-4 weeks, so these findings were consistent with the expected timeline of corticosteroid effect. No adverse events were reported. ${ }^{(12)}$

\section{MATERIALS AND METHODS}

This study was conducted on 36 adult female rats, 3 months old weights ranged between $150 \mathrm{gm}$ $200 \mathrm{gm}$, not pregnant, with normally functioning temporomandibular joint.

After approval of the research ethics committee, rats were selected from the animal house in faculty of medicine, Cairo University.

Rats were injected by Methylprednisolone acetate injectable suspension (DEPO-MEDROL) * $40 \mathrm{mg} / \mathrm{ml}$ according to the grouping.

\section{Animal grouping:}

The rats were divided into three groups: A, B, and C. every group is divided into (2) sub-groups. Each sub-group had (6) rats; so the groups and the sub-groups are:

$$
\text { Group A: } \mathrm{A}_{1}, \mathrm{~A}_{2} \text { Group B: } \mathrm{B}_{1}, \mathrm{~B}_{2} \text { Group C: } \mathrm{C}_{1}, \mathrm{C}_{2}
$$

\footnotetext{
* Depo-Medrol: Pharmacia \& Upjohn co. division of Pfizer Inc New York. NY10017
} 


\section{All rats of the group A were injected one time:}

- The sub-group $\mathrm{A}_{1}$ were sacrificed after (1) week from injection.

- The sub-group $A_{2}$ were sacrificed after (2) weeks from injection.

\section{All rats of the group $B$ were injected two times at} $(0,6)$ weeks:

- The sub-group $B_{1}$ were sacrificed after (1) week from last injection.

- The sub-group $B_{2}$ were sacrificed after (2) weeks from last injection.

\section{All rats of the group $C$ were injected three times at} (0,6, and 12) weeks:

- The sub-group $C_{1}$ were sacrificed after (1) week from last injection.

- The sub-group $\mathrm{C}_{2}$ were sacrificed after (2) weeks from last injection.

The dose for intra-articular administration depends upon the size of the joint according to the manufacture, for a small joint the range of dose was 4-10mg of depo-medrol by insulin syring.

The animals were sacrificed by overdose of anaesthesia, according to each group timming.

Preparation for histological analysis: The condylar area (TMJ) were dissected and immersed in $10 \%$ formalin, semi-serial $4 \mu \mathrm{m}$ histological sections were made and stained with Haematoxlin and $\operatorname{Eosin}(\mathrm{H} \& \mathrm{E})$.

\section{RESULTS}

Examination of normal TMJ microscopic structure for rats was proceeding for detection of any deviation from normal within the three groups.

\section{Group A:}

\section{-Histological examination of subgroupA1 and A2}

Bone marrow spaces became more numerous and wide after one week and 2 weeks from the injection

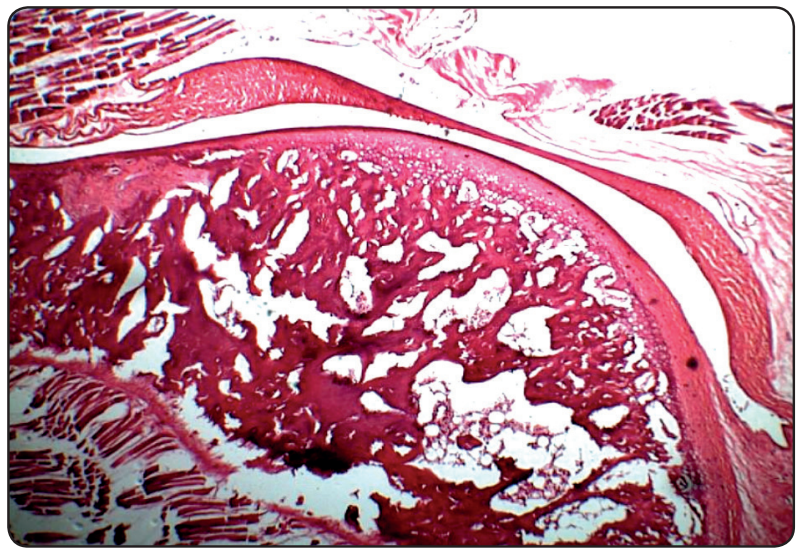

Fig. (1) photomicrograph of the condyle for subgroup A2 showing wide marrow spaces and thinning of the disc. (Hematoxylin and eosin, original magnification $=\mathrm{x} 100$ ).

in the condylar head and temporal bone, the content of marrow spaces filled with fibrous tissues, no inflammatory cells, the hyaline cartilage covering the condylar head appeared normal, no changes in the articular disc and retodiscal tissues, in some cases thinning of the articular disc was noticed.

\section{Group B:}

\section{-Histological examination of subgroupB1 and B2}

Widening of marrow spaces in both temporal bone and condylar head with fibrous tissue content of the marrow spaces ,and the hyaline cartilage of the condyle appeared normal, no changes in disc and retrodiscal tissues with no signs of inflammation.

\section{Group C}

\section{-Histological examination of subgroupC1 and C2}

Also widening of the bone marrow spaces in the condylar head and temporal bone, but with signs of inflammatory invasion and fatty degeneration showed in all cases, the disc and retrodiscal tissue still not affected but some cases showed thinning of the disc but no perforation, no bone resorption of the condylar head, presence of reversal line which represent new bone formation became more numerous. 


\section{DISCUSSION}

There is a controversy about the effect of corticosteroids injection on both bone and soft tissues. This study conducted on temporomandibular joint in its normal healthy state to study the short term deleterious effect of corticosteroids regarding the number of injections.

In 1985 by KOPP et al., ${ }^{(13)}$ The short-term effect of intra-articular injections of sodium hyaluronate and a corticosteroid (betamethasone) was compared in the temporomandibular joint the drug was injected twice into the superior joint compartment of the TMJ with a two-week interval between injections. Both drugs reduced the symptoms and signs significantly, and no statistically significant difference.

In 2004 Arroll et al., ${ }^{(14)}$ support the equivalent dose of prednisone varied from $6.25 \mathrm{mg}$ to $80 \mathrm{mg}$, and found that the number needed to treat and obtain one improvement was between 1.3 and 3.5. No important harms were reported other than transient redness and discomfort.

In 2001 Guidolin et al., ${ }^{(15)}$ the methylprednisolone (Depo-Medrol) treated group of patients indicated a protective effect of intra-articular corticosteroids on cartilage lesions, but no significant changes in the ultra structural features of the chondrocytes. It has been suggested that the capability of the corticosteroids to inhibit the stimulation of protease synthesis induced by inflammatory cytokines could be the basis of their beneficial effect when administered intra-articularly.

In 2009 Hauser, ${ }^{(16)}$ mentioned that the rate of the inhibitory effect of intra-articular hydrocortisone on cartilage protein synthesis was about twice that of the observed rate for corticosteroids given by intramuscular route, this resulted in thinning of the cartilage.

\section{CONCLUSION}

Based on the results of the current study:The effect of corticosteroids on the TMJ healthy bony structures detected with the use of the least dosage and single injection, No significant deleterious effects were detected histologically in the current study on other joint structures especially cartilage with steroids use regardless the dose and the number of injections, Repetitive intra-articular steroid injections proved to be safe taking in consideration the used dosage and injection intervals.

\section{ACKNOWLEDGEMENT}

Prof. Dr. Atef Abdel-Hamid Fouda Professor of Oral and Maxillofacial surgery, Faculty of Oral and Dental Medicine, Cairo University.

\section{REFERENCES}

1- Okeson Jp: Management of Temporomandibular disorders and occlusion. Chap 1, Functional Anatomy and Biomechanics of the Masticatory System, sixth edition, USA: Mosby, 2008, 9, 13, 14.

2- Alomar X, Medrano J, Cabratosa J, Clavero JA, Lorente M, Serra I, Monill JM and Salvador A: Anatomy of the Temporomandibular Joint. Seminar ultrasound CT MRI, 2007, 28:170-183.

3- Milam SB: TMJ osteoarthritis. In: Laskin DM, Greene CS, Hylander WL eds. TMDs. An evidence-based Approach to Diagnosis and Treatment. Hanover Park, IL: Quintessence Publishing Co., 2006, 105-123.

4- Abubaker AO: TMJ arthritis. In: Laskin DM, Greene CS, Hylander WL eds. TMDs. An Evidence-based Approach to Diagnosis and Treatment. Hanover Park, IL: Quintessence Publishing Co., 2006, 229-248.

5- Okeson JP, Ed: Fundamentals of Occlusion and Temporomandibular Disorders. Signs and Symptoms of Temporomandibular Disorders, Sixth edition,St. Louis: C.V. Mosby, 1985, 8:47,

6- Quinn JH: Pathogenesis of temporomandibular joint chondromalacia and arthralgia. Oral Maxillofac Surg Clin North Am, 1989, 1:47-57.

7- Cole BJ and Schumacher HR Jr: Injectable corticosteroids in modern practice. J Am AcadOrthop Surg, 2005, 13(1):37-46 
8- Centeno LM and Moore ME: Preferred intraarticular corticosteroids and associated practice:a survey of members of the American College of Rheumatology. Arthritis Care Res, 1994, 7(3):151-155.

9- Lavelle W, Lavelle ED and Lavelle L: Intra-Articular Injections. Anesthesiology Clinics, 2007, 25: 853-862.

10- Hossain MA, park J, choi SH and kim G: Dexamethasone induces apoptosis in proliferative canine tendon cells and chondrocytes. Vet Comp Orthop Traumatol, 2008, 21:337-342.

11- Schindler C, Paessler L, Eckelt U and Kirch W: Severe temporomandibular dysfunction and joint destruction after intra-articular injection of triamcinolone. J. Oral Pathol. Med, 2005, 34: 184-186.

12- Alstergren P, Appelgren A, Appelgren B, Kopp S, Lundeberg $\mathrm{T}$ and Theodorsson $\mathrm{E}$ : The effect on joint fluid concentration of neuropeptide $\mathrm{Y}$ by intra-articular injection of glucocorticoid in temporomandibular joint artvhritis. Acta Odontol. Scand, 1996, 54: 1-7.
13- Kopp S, Wenneberg B, Haraldson T and Carlsson G E: The short-term effect of intra-articular injections of sodium hyaluronate and corticosteroid on temporomandibular joint pain and dysfunction. Journal of Oral and Maxillofacial Surgery, 1985, 43(6): 429-435.

14- Arroll B and Goodyear-Smith F: Corticosteroid injections for osteoarthritis of the knee: meta-analysis. Primary care, 2004, 328 (7444): 869.

15- Guidolin D D, Ronchetti I P, Lini E, Guerra D and Frizziero L: Morphological analysis of articular cartilage biopsies from a randomized, clinical study comparing the effects of $500-730 \mathrm{kDa}$ sodium hyaluronate (Hyalgan $\AA$ ) and methylprednisolone acetate on primary osteoarthritis of the knee, Osteoarthritis and Cartilage, 2001, 9: 371-381.

16- Hauser RA: The Deterioration of Articular Cartilage in Osteoarthritis by Corticosteroid Injections. Journal of prolotherapy, 2009, 1:107-123. 